\title{
Injection of bone marrow mesenchymal stem cells in the borderline area of infarcted myocardium: Heart status and cell distribution
}

Hao Zhang, MD, PhD, ${ }^{a, *}$ Peng Song, MD, ${ }^{a, *}$ Yue Tang, MD, PhD, ${ }^{b}$ Xiao-ling Zhang, BS, ${ }^{a}$ Shi-hua Zhao, MD, ${ }^{\mathrm{c}}$ Ying-jie Wei, PhD, and Sheng-shou Hu, MD ${ }^{a}$

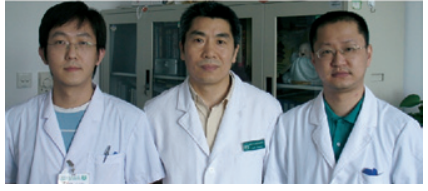

Drs Song, Hu, and Zhang (left to right)

Supplemental material is available online.
From the Research Center for Cardiac Regenerative Medicine, the Ministry of Health and Department of Surgery, ${ }^{\mathrm{a}}$ the Animal Research Center, ${ }^{b}$ and the Unit of Magnetic Resonance Imaging, ${ }^{\mathrm{c}}$ Fu Wai Hospital, Beijing, China.

Supported by the National Eleven-Five Year Project (S.H), National Scientific Foundation of China (30500498) and Beijing Nova Project (2006A85) (H.Z).

Received for publication April 19, 2007; revisions received June 25, 2007; accepted for publication July 19, 2007.

Address for reprints: Sheng-Shou Hu, MD, Chief, Department of Surgery, Director, Research Center for Cardiac Regenerative Medicine, President, Cardiovascular Institute \& Fu Wai Hospital, Professor, Chinese Academy of Medical Sciences, 167A Beilishilu, Beijing 100037, Peoples Republic of China (E-mail: shengshouhu@yahoo.com).

*The first two authors contribute equally to this work.

J Thorac Cardiovasc Surg 2007;134:1234-40 $0022-5223 / \$ 32.00$

Copyright $\odot 2007$ by The American Association for Thoracic Surgery

doi:10.1016/j.jtcvs.2007.07.019
Objective: This study aimed to test the distribution of intramyocardially injected cells in variations in heart status in a porcine model of myocardial infarction.

Methods: Bone marrow-derived mesenchymal stem cells were obtained from male swine and labeled with iron oxide during culture. One week after creation of a myocardial infarction in female swine, the survivors were randomly divided into 4 groups. Cardiopulmonary bypass was set up to arrest the heart, and then labeled cells $\left(1 \times 10^{8}\right)$ were intramyocardially injected into the border zone of the infarcted zone in group $1(\mathrm{n}=6)$. The same volume of cells was grafted into the beating heart in group $2(\mathrm{n}=6)$. In groups 3 and 4 , saline was injected in either the arresting or beating heart. Three days later, cell distribution was assessed by $\mathrm{T} 2 *$ change with magnetic resonance imaging and sex-determining region on Y-chromosome (SRY) with quantitative polymerase chain reaction.

Results: The cells were identified in the heart, spleen, lung, and liver. Most injected cells were localized in the myocardium in groups 1 and 2; however, the amount of cells was much higher in group 1 (T2* change: $22.3 \pm 2.2$ vs $17 \pm 0.84$; SRY gene: $0.15 \pm 0.062$ vs $0.072 \pm 0.003)$.

Conclusions: Even after intramyocardial injection, many cells migrated to extracardiac organs, especially to the spleen. Our results indicated that injection in the arresting heart could favor retaining more cells in the myocardium. Thus, it was an optimal approach to deliver mesenchymal stem cells during open chest surgery.

$\mathrm{S}$ tem cell therapy has emerged as a promising approach for the treatment of myocardial infarction (MI). The delivery approaches play a critical role in the process of supplying exogenous cells for replacing and repairing damaged heart tissue. Intracoronary infusion of freshly isolated bone marrow (BM)-derived mononuclear cells has been attempted in many clinical trails since $2002 .{ }^{1}$ Recently, a series of randomly designed studies confirmed the safety and feasibility of this approach; however, it also showed that such an uncultured cell therapy could have no effect or contribute to only mild improvement of heart function. ${ }^{2}$ There is no doubt that the process of purification and proliferation would increase the amounts of progenitor cells and thus improve the efficiency of cell therapy. However, intracoronary infusion of cultured cells could result in embolism of the coronary system and cause microinfarction. ${ }^{3}$

Intramyocardial delivery into the target area can be achieved by transendocardial and transepicardial routes. Intramyocardial injection (IMI) could be hybrided with open-chest coronary surgery, and, thus, it became one of the convenient approaches by which cardiac surgeons could deliver the cells. Besides the delivery routes, the heart status could also affect the migration and actual fate of implanted cells. However, to date, little is known about the relation between cell distribution and 


$$
\begin{array}{ll}
\text { Abbreviations and Acronyms } \\
\begin{array}{ll}
\text { BM } & =\text { bone marrow } \\
\text { IMI } & =\text { intramyocardial injection } \\
\text { MI } & =\text { myocardial infarction } \\
\text { MRI } & =\text { magnetic resonance imaging } \\
\text { MSCs } & =\text { mesenchymal stem cells } \\
\text { qRT-PCR } & =\text { quantitative real-time polymerase chain } \\
& \text { reaction } \\
\text { SRY } & =\text { Y-chromosome gene }
\end{array}
\end{array}
$$

heart status. Therefore, this preclinical study tested the distribution of the cultured BM mesenchymal stem cells (MSCs) with IMI in both the arresting and the beating heart in a porcine MI model.

\section{Materials and Methods}

The study was performed in accordance with the guidelines of the "Regulation to the Care and Use of Experimental Animals" (1996) of the Beijing Council on Animal Care. Chinese miniature swine came from the China Agricultural College. All animal experimental procedures were approved by the Ethics Committee for Animal Study in Fu Wai hospital.

\section{MSC Preparation}

$\mathrm{BM}$ was aspirated from the iliac crest of male swine. A standard protocol was then used to obtain the MSCs, as previously described. ${ }^{4}$ MSCs were expanded with 4 to 5 passages and yielded adequate cells for transplantation.

\section{Cell Labeling}

Confluent cells were incubated with a mixture of superparamagnetic iron oxide (SPIO; Resovist, Germany) $(50 \mu \mathrm{g} / \mathrm{mL})$ and poly-L-lysine (400 ng/mL; Sigma Chemical Co, St Louis, Mo) for 48 hours before cell transplantation, as previously described. ${ }^{5}$ The viability of the labeled cells was evaluated by trypan blue exclusion test and the labeling efficiency was measured by Prussian blue staining.

\section{Creation of Animal MI Model and Groups}

Twenty-seven female swine $(25-35 \mathrm{~kg}$ ) were included in the study. An occlusive angioplasty balloon was advanced into the proximal left anterior descending coronary artery via a percutaneous approach. Acute MI was induced by inflating the balloon for 90 minutes followed by artery perfusion. ${ }^{6}$

Seven days after MI, the surviving animals were randomly assigned to 4 groups: cell transplantation in the arresting heart (group 1, $\mathrm{n}=6$ ), cell transplantation in the beating heart (group 2, $\mathrm{n}=6$ ), saline injection in either the arresting or the beating heart (groups 3 and $4, \mathrm{n}=6$, respectively).

\section{Preparation for Cardiopulmonary Bypass and Withdrawal}

Systemic heparinization was performed at $300 \mathrm{IU} / \mathrm{kg}$ body weight. Following the institute's protocol for preparing cardiopulmonary bypass, the chest was opened, the arterial cannula was inserted into the aorta, and a dual-stage atriocaval cannula was placed in the right atrium. Then the ascending aorta was clamped and the cardioplegic solution was perfused to induce cardiac arrest. After the cell transplantation or saline injection, the body temperature was rewarmed and the aortic clamp was released. Generally, the heart would beat again in sinus rhythm.

\section{Cell Transplantation}

Seven days after the creation of the MI model, the chest was opened through the left second intercostal space. After the identification of the borderline area of MI zone, the labeled MSCs in suspension $\left(2 \mathrm{~mL}, 1.0 \times 10^{8}\right.$ cells $)$ were injected into 4 sites $(0.5$ $\mathrm{mL}$ in every site), with marked sutures left to seal the puncture hole. The needles were punctured at an oblique angle to prevent the cells from being injected into the ventricular cavity; furthermore, the injection was started only after making sure no blood has been sucked back to the syringe.

The same volume of saline was injected in the same way in the cell transplantation groups.

\section{Magnetic Resonance Imaging Study}

All animals underwent magnetic resonance imaging (MRI) 24 hours before cell transplantation or saline injection and then again 72 hours after the procedure. The MRIs were acquired with the Avanto 1.5-T MR scanner (Siemens AG, Berlin, Germany).

Myocardial iron deposition could be quantified by myocardial $\mathrm{T} 2 *$ in the signal void region. $\mathrm{T} 2 *$ is related to $\mathrm{T} 2$ by summation of tissue relaxation (T2) and magnetic inhomogeneity (T2 prime, $\mathrm{T} 2{ }^{\prime}$ ), and $\mathrm{T} 2 *$ sequence had a greater sensitivity to iron deposition than T2 sequence. Each scan included the measurement of heart, liver, spleen, and kidney T2*. For the measurement of myocardial T2*, MRI was performed at multiple time points using fast gradient echo pulse sequences (flip angle $35^{\circ}$, matrix $128 \times 256$ pixels, field of view $30 \mathrm{~cm}$, sampling bandwidth of $810 \mathrm{kHz}$ ) in standard segmented, electrocardiogram-gated, and breath-held examinations. ${ }^{7}$ In vivo $\mathrm{T} 2 *$ relaxation rates were determined by gated fast gradient echo with multiple echo times (1.89-20.9 ms). A gating delay time of $0 \mathrm{~ms}$ after the R-wave was chosen to obtain myocardial images in a consistent position in the cardiac cycle irrespective of the heart rate. A region of interest in the anterior left ventricular wall that is distant from the cardiac veins was measured. For image signal analysis, we used in-house designed software (CMR tools, Imperial College, London, United Kingdom).

The liver, spleen, and kidney $\mathrm{T} 2 *$ were determined as standard protocol. ${ }^{8}$ The same imaging protocols as those used for imaging the heart were used. A large region of interest was chosen in a homogeneous area of parenchyma without blood vessels.

\section{Tissue Harvest and Immunohistochemical Examination}

The animals were humanely killed after postoperative MRI study. About 2-cm square heart tissues were collected in each of the injection sites. The harvested tissues were dissected into two pieces. One was frozen in liquid nitrogen until DNA extraction for quantitative analysis of male cells with quantitative real-time polymerase chain reaction (qRT-PCR) test. Another was paraffin embedded for Prussian blue staining. The remote noninfarcted myo- 
cardium and the infarcted myocardium were also harvested and handled in the same way.

Samples of the lung and liver were taken from central locations and from the edge of each lobe. Spleen samples were taken from central locations and edge tissue. Kidney samples were taken from cortex and medulla tissue. Each sample was 2-cm square and treated in the same manner as heart tissue.

The samples from heart and spleen were chosen for immunohistochemical examination to detect macrophages (Calprotectin Ab-1; Lab Vision Corporation, Fremont, Calif).

\section{qRT-PCR}

qRT-PCR with the ABI Prism 7700 Sequence Detection System was used to quantify donor male swine cells. It was performed with SYBR-Green (Applied Biosystems, Foster City, Calif). The genomic DNA taken from male MSCs was used to obtain a standard curve. The forward primer was AAAGCGGACGATTACAGC and the reverse primer was TTTGCATTTGAGGGTTCT. The RT-PCR protocol consisted of an initial step at $94^{\circ} \mathrm{C}$ for 2 minutes, followed by 38 cycles: $94^{\circ} \mathrm{C}$ for 30 seconds' denaturation, annealing at $50^{\circ} \mathrm{C}$ for 30 seconds, and elongation at $72^{\circ} \mathrm{C}$ for 30 seconds. $^{9}$

To obtain a standard curve, we extracted genomic DNA of MSCs and measured the concentration by spectrophotometry. A sample was diluted to produce samples, which had a range from 1 $\mu \mathrm{g} / \mu \mathrm{L}$ to $1 \times 10^{-4} \mu \mathrm{g} / \mu \mathrm{L}$ concentration. A serial 10 -fold dilution of the DNA from male swine MSCs was tested 5 times in separate experiments.

The numbers of implanted male cells in tissues were evaluated by RT-PCR amplification of the male cell-specific sex-determining region on Y-chromosome (SRY) gene. The numbers of the implanted male cells residing in the myocardium, lungs, liver, kidney, and spleen were compared.

\section{Statistical Analysis}

All values were reported as means \pm SEM. SPSS Software for Windows (version 10.0; SPSS, Inc, Chicago, Ill) was used for analysis.

Differences in organ $\mathrm{T} 2 *$ change of 4 groups were compared by the least-significant difference (LSD) 1-way analysis of variance test. Unpaired $t$ test was performed to compare the SRY gene expression between different groups.

\section{Results}

\section{Mortality}

Three pigs died of ventricular arrhythmia, which occurred during the creation of MI, and 3 died owing to the failure of preparation of cardiopulmonary bypass in our early series. These animals were excluded from the final analysis.

\section{Myocardial Images and T2* Change}

In MRI visualization of myocardium with a short-axis slice of mid-left ventricle, signal void corresponding to the injection sites were seen in groups 1 and 2 (Figure 1, $a$ and $b$ ). There was no significant difference in $\mathrm{T} 2 *$ change between groups 3 and 4 . Heart T2* change of the cell transplantation groups was significantly higher than that of control groups.
Group 1 had a higher T2* change than group 2 in the heart $(22.3 \pm 2.2$ vs $17.00 \pm 0.84 ; P=.008)$ (Figure $1, c)$.

$\mathrm{T} 2 *$ changes of the cell injection groups were significantly higher than those of the control groups in the liver and spleen $(P<.05)$, but there was no statistical difference in the kidney $(P>.05)$ (Figure E1). Group 1 had less $\mathrm{T} 2 *$ change in the spleen than did group $2(7.7 \pm$ 0.73 vs $13.28 \pm 1.14 ; P<.001$ ) (Figure $1, c$ ).

The MI area and heart function were also compared, but we did not observe any differences among any groups (Table E1).

\section{qRT-PCR for SRY Gene}

In groups 3 and 4, no SRY gene was detected in any tissues. In groups 1 and 2, many more male cells were detected in the heart and spleen than those found in other organs. Furthermore, compared with group 2, group 1 has higher male cell retention in the myocardium $(0.150 \pm 0.062$ vs $0.072 \pm 0.004 ; P<.001)$ and less retention in the spleen $(0.131 \pm 0.001$ vs $0.233 \pm 0.017 ; P<.001)$ (Figure 2). In the noninfarcted myocardium, no male cells were detected in any cell transplantation group.

In the liver, group 1 had higher cell retention than group $2(0.017 \pm 0.0009$ vs $0.009 \pm 0.0005 ; P<.001)$, but there was no statistically significant difference in the lung $(0.0015 \pm 0.0009$ vs $0.0016 \pm 0.0009 ; P>.05)$. We did not detect any implanted male cells in the kidney.

\section{Histologic Analysis}

In the cell transplantation groups, the implanted cells mostly localized in the injection site. No injected cell was identified in the remote noninfarcted myocardium and only few Prussian blue-positive cells could be found in the infarcted myocardium. Compared with group 2 (Figure 3,b), there are more clustered cells in the border zone of $\mathrm{MI}$ in group 1 (Figure 3,a).

Except for the heart, the spleen had more Prussian bluepositive cells than had any other organ in both cell transplantation groups, and they were mainly distributed in the red pulp; furthermore, group 2 (Figure 3,d) had much more Prussian blue-positive cells than group 1 (Figure 3,c).

The Prussian blue-positive cells were detected in hepatic sinusoid around the central vein of the hepatic lobule (Figure $3, e)$. It was relatively hard to find the positive cells in the lungs, and only a few cells were detected over the pulmonary interstitial substance, blood vessel side, and interlobular septum (Figure 3, f). We did not find any positive cells in the kidney in any cell transplantation groups. No positive cells were identified in any organs in any of the control groups.

Although macrophages were presented in infarcted myocardium and spleen, the majority of Prussian blue-positive 

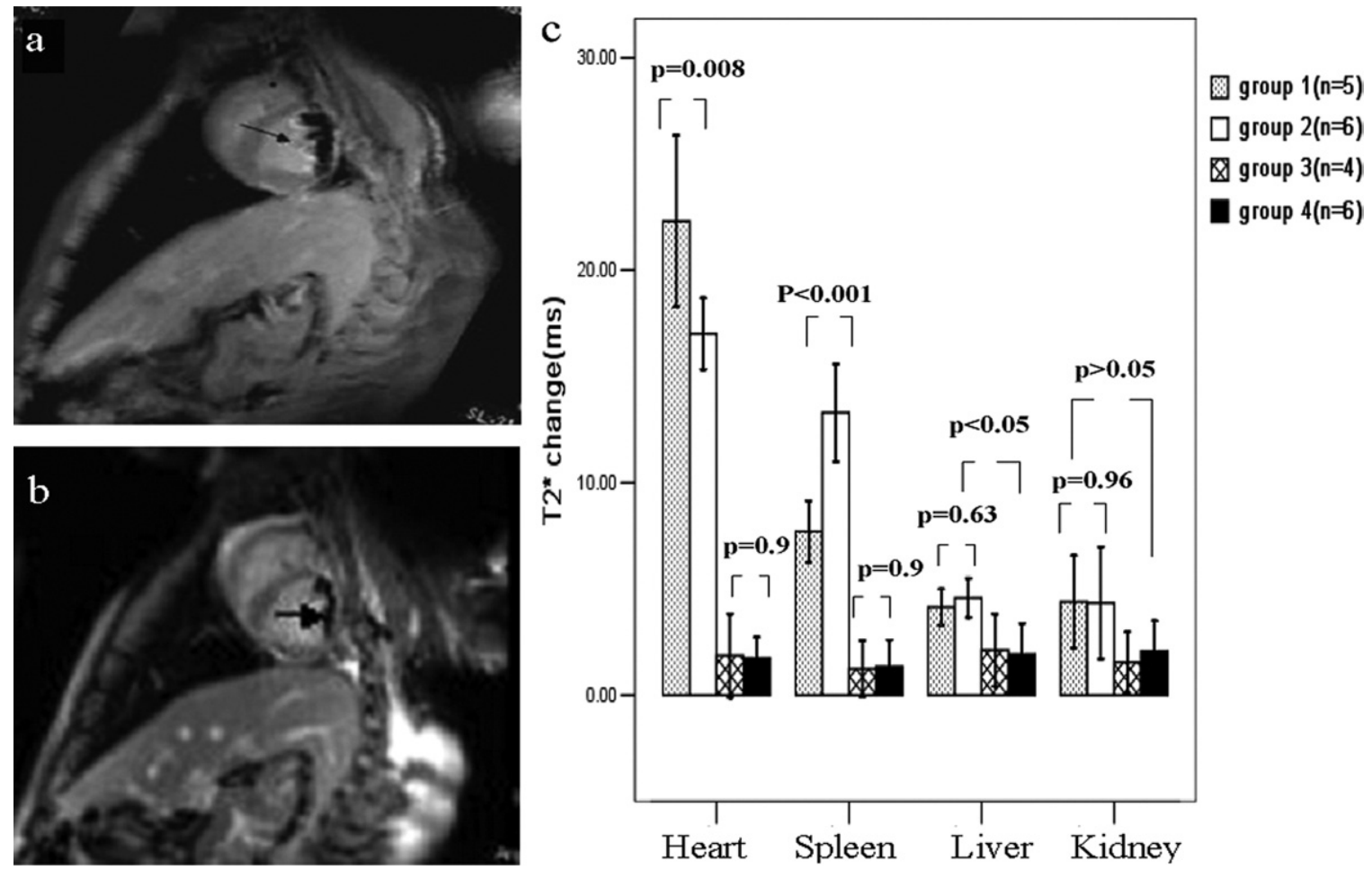

Figure 1. Magnetic resonance visualization of myocardium and the comparison of $\mathbf{T}^{*}$ change in different organs. The dark arrow indicates the signal void corresponding to the injection sites in groups 1 (a) and 2 (b). Group 2 showed weaker signal void than group 1 (c). (T2* change $=T 2^{*}{ }_{\text {pre-cell transplant }}-\mathrm{T} 2{ }^{*}{ }_{\text {post-cell transplant). }}$ ).

cells had not been double stained with Calprotectin Ab-1 (Figure 3, $g$ and $h$ ).

\section{Discussion}

BM-derived MSC has been demonstrated to be a suitable cell resource for regenerative purposes for treating MI. ${ }^{10}$ Chen and his colleagues ${ }^{11}$ infused autologous MSCs into the coronary arteries for patients with acute MI. Although no additional microinfarction was observed in Chen's study, transplantation of such large cells through the coronary artery still has the great potential for microembolization. The direct IMI route of administration of MSCs could be the easiest and most effective way for cardiac surgeons while they perform operations such as coronary artery bypass grafting. From the surgeon's view, the impact of beating (off-pump) or arrested (on-pump) coronary surgery on the cell redistribution would be an important issue. Therefore, in this study, 3 days after cell IMI, we investigated the body distribution of the injected cells; furthermore, the influence of variations in heart status for cell distribution was studied.

The major findings in this preclinical model are that (1) the majority of the transplanted MSCs were retained in the injection site, (2) although the cells were injected intramyocardially, they also migrated to other organs, especially to the spleen, and (3) the arresting heart could favor retaining more injected cells in the myocardium.

MRI has been proposed as a novel noninvasive approach to track the iron-labeled transplanted cells in vivo. ${ }^{12}$ Besides MRI, nuclear medical technologies such as positron emission tomography were also widely used to describe the cell body distribution. However, owing to the short half-life of the radioactive marker, the nuclear scintigraphic tracking might degrade dramatically during the first 24 hours. ${ }^{13} \mathrm{We}^{5}$ have confirmed the SPIO was a safe and efficient marker for the relative long-term cell tracking in the injured myocardium. MRI could offer the high spatial resolution of labeled cell location and the T2* value could also be compared for the quantification of implanted cells. SPIO signal could be "diluted" if cells divide; however, in the early stage of cell transplantation, the grafted cells would face the challenge from the new environment and strive to survive rather than proliferate. Hence, in this study we did not believe that the "dilution effect" would be a confounding factor. However, some factors, including the hemorrhage caused by reperfusion injury, might bias the results of cell distribution. ${ }^{14}$ Therefore, together with MRI analysis, we also used the qRT-PCR as an established method for accurate and sensitive quantification for implanted cells. qRT-PCR was first 


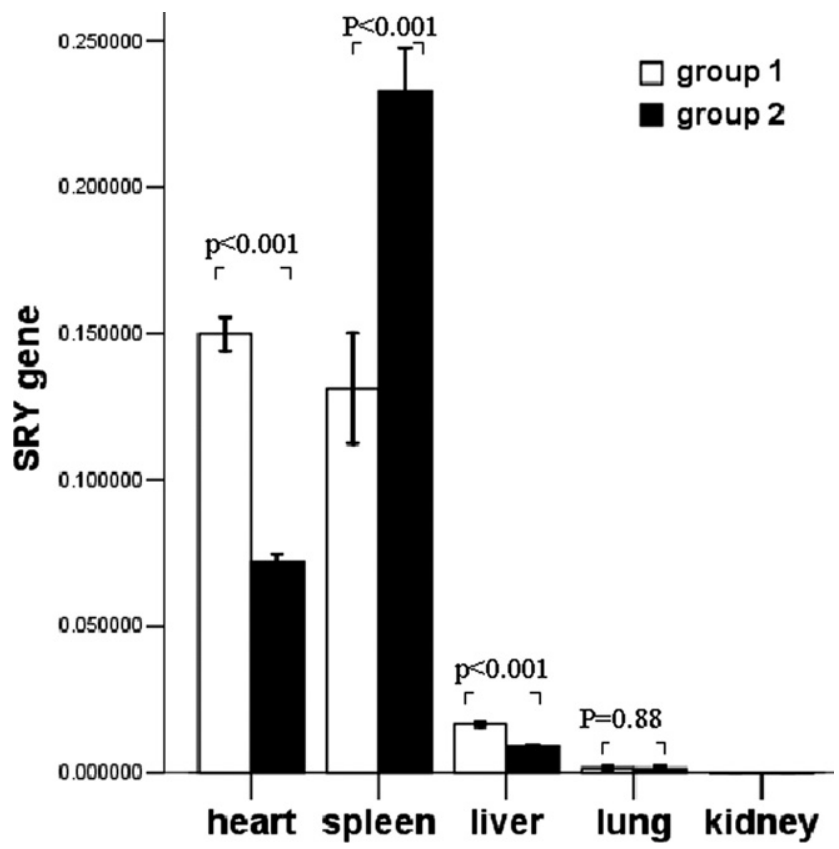

Figure 2. RT-PCR amplification of the transplanted male cellspecific SRY gene in selected sample from different organs after cell transplantation. $R T-P C R$, Real-time polymerase chain reaction; $S R Y$, Y-chromosome gene.

introduced to evaluate the donor male leukocyte survival in female recipients. ${ }^{15}$ Yasuda and his colleagues ${ }^{9}$ applied qRT-PCR to study the implanted cell survival in a rat MI model. In our study, the results of qRT-PCR were consistent with the MRI findings.

Locally direct IMI was more site specific with less systemic engraftment than other delivery approaches. ${ }^{16}$ However, the locally injected cells still migrated to extracardiac organs. Hou and his colleagues ${ }^{17}$ found that even after intramyocardial injection, most peripheral blood mononuclear cells would be trapped in the lung. Owing to the small cell size, the mononuclear cells could be drained into myocardial veins or lymphatics and then migrate to the right ventricle and lung. Our results were similar to those reported by the researchers who injected the cells directly into the left ventricular cavity. ${ }^{18}$ In the study by Barbash and associates, ${ }^{18}$ after cell infusion in the left ventricle, lung trapping was bypassed and more cells were trapped in the spleen and liver. Considering the above observations, we hypothesized that the injected MSCs would mostly be drained through the collateral channels and ventricular lumen in the borderline area of the MI and then arrive at the left ventricle. Finally, the cells were pumped into the aorta and resided in the spleen and liver. Furthermore, we found that most of the Prussian blue-positive cells in the spleen were negative for the macrophage marker Calprotectin Ab-1, which suggested they were originally injected MSCs.
Besides the leaked cells, we found that the majority of cells still settled at the sites of injection. No cells were found in the remote noninfarcted myocardium and only a few cells "homed" to the center of myocardial scar tissue. This suggested that the local MSCs responded to the injury signal and migrated to the damaged myocardium. However, owing to the large cell size and different expressed adhesion molecules, only a very small number of MSCs could move to the remote infarcted myocardium.

In the ongoing clinical trials performed by the surgeons, either BM-derived $\mathrm{CD}_{133^{+}}$cells or cultured myoblasts were injected into the borderline area of MI under cardioplegic arrest. ${ }^{19,20}$ Teng and her colleagues ${ }^{21}$ injected the microspheres and found the massive mechanical loss by squeezing the microspheres out of the myocardium while the heart was beating. In our study, IMI in the arresting heart helped more cells reside in the myocardium. Interestingly, an inverse relationship between the numbers of cells that were detected in the heart and spleen was observed. Since the purse-string suture was placed on the epicardium to seal the puncture hole in each cell transplantation group, the backward leakage could be similar between the beating and arresting heart. We presumed that the myocardial contractile force augmented the washout of injected cells to the left ventricular cavity and thus decreased the number of cells in the myocardium. Hence, for a patient receiving cell transplantation and coronary surgery, on-pump techniques and a motionless myocardium were critical for the prevention of excess cell loss in the heart. On the other hand, we needed to do more studies to clarify the role of systemic filter organs in the cell redistribution for the improvement of efficiency of IMI.

There are some limitations in the present study. First, we only studied the early phase of cell body distribution. Ultraearly and late dynamic imaging of transplanted cells will be necessary in our future study. Second, although we followed the same protocol as Yasuda and his colleagues ${ }^{9}$ to evaluate the number of male cells in different organs, we did not report the number and percentage of retained cells in each organ. In Yasuda's study, the experimental model was the rat. Owing to the smaller animal size, the entire organs were harvested and prepared for qRT-PCR study. In the present study, it was impossible to extract DNA from all parts of tissues from the swine heart or any other extracardiac organ. Therefore, we only selected a typical tissue sample from every organ and failed to report the percentage relative to the initial number of injected cells. Third, the myogenic differentiation of grafted cells was usually identified several weeks after cell injection. ${ }^{22}$ Thus it would be very difficult to find the evidence of differentiation and improved heart function in the present study. However, the impact of variations in heart status on differentiation of MSCs and heart function would be evaluated in the future long-time study. 

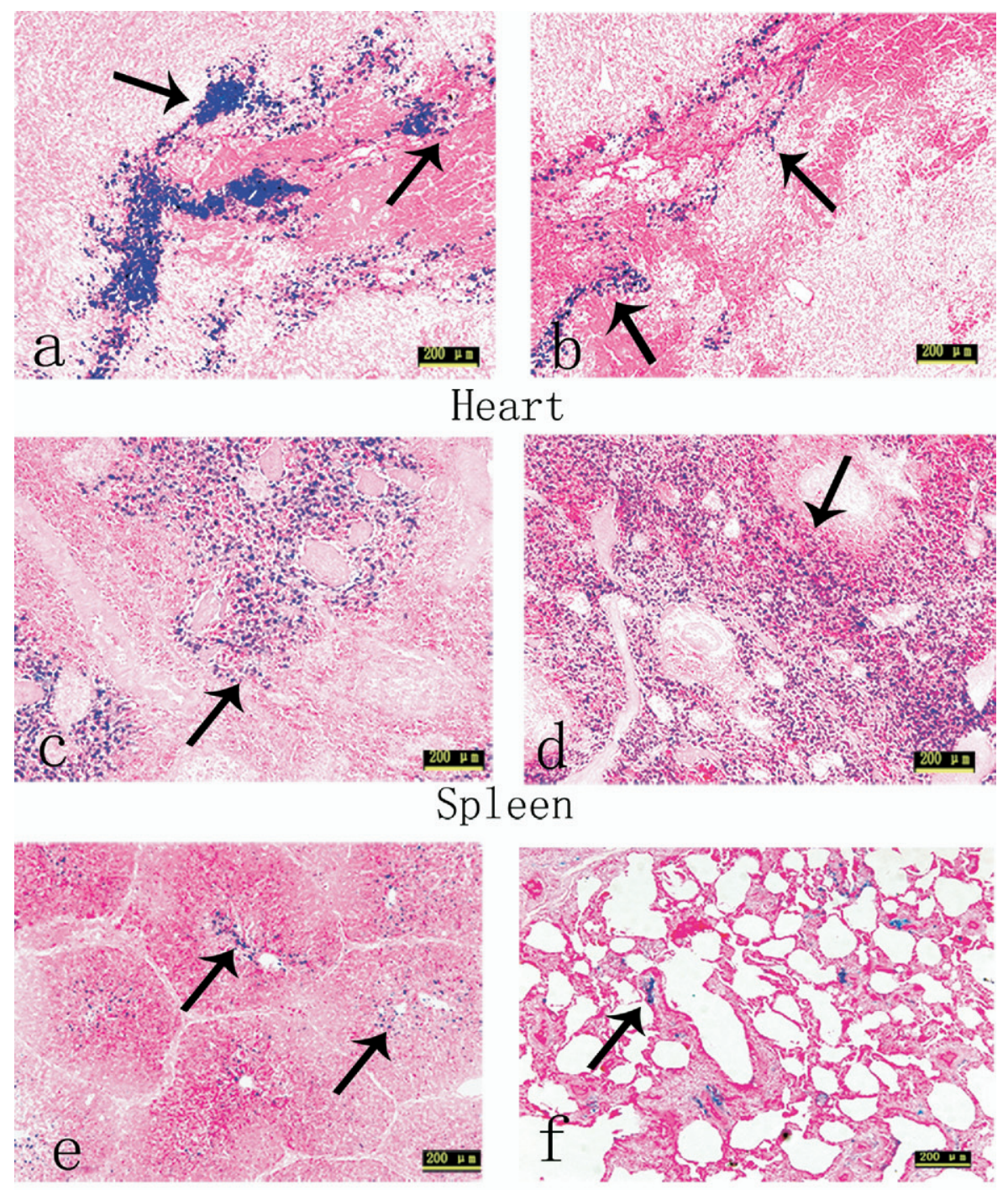

\section{Liver}

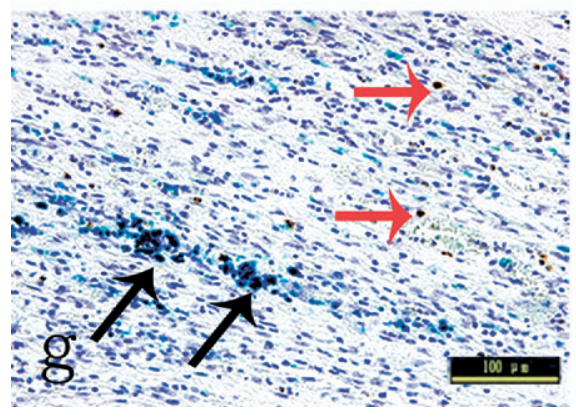

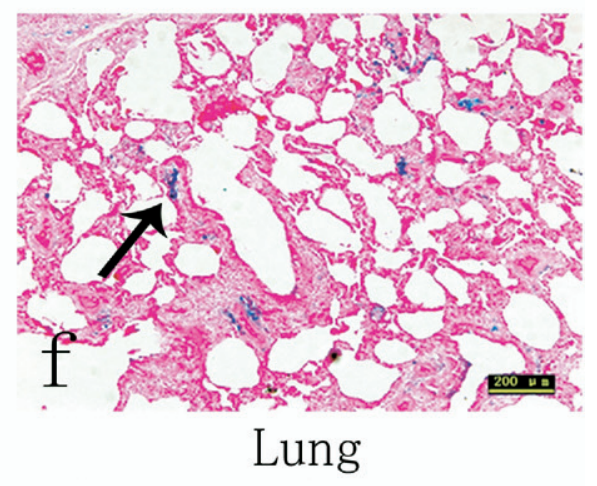

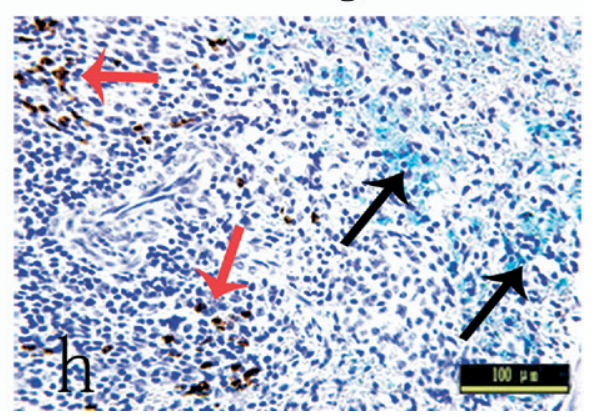

Figure 3. Identification of the Prussian blue-positive cells in different organs after cell transplantation. The positive cells were mostly localized in the myocardium and spleen. However, more cells could be detected in the myocardial injection sites and fewer cells in the spleen in group 1 (a and c). Fewer positive cells could be found in the liver and lung (e and f). Calprotectin Ab-1 staining showed most of the Prussian blue-positive cells in the heart (g) and spleen (h) had not originated from macrophage. (Black arrow indicated the Prussian blue-positive cells; red arrow indicated the Calprotectinpositive macrophage.)
Finally, the allogenic male MSCs were used as a cell resource in this study. Although MSCs are supposed to be immuneprivileged $^{22}$ and we did not find CD3-positve T lymphocytes (data not shown), a few macrophages were scattered in infarcted myocardium, which suggested the mild immune rejection could exist in this sex-mismatched study.
In conclusion, this preclinical study for the first time elucidated cell cardiac and extracardiac distribution after the IMI of MSCs. Furthermore, we found that the arresting heart during the injection could help more cells reside in the myocardium. We believe that these results also have important implications for other exogenous cultured 
stem cells, including embryonic stem cells, in future clinical trials.

We thank Dr Minjie Lu for assistance in the MRI analysis and Dr Chong Shen for assistance in statistical analysis.

\section{References}

1. Strauer BE, Brehm M, Zeus T, Köstering M, Hernandez A, Sorg RV, et al. Repair of infarcted myocardium by autologous intracoronary mononuclear bone marrow cell transplantation in humans. Circulation. 2002;106:1913-8.

2. Rosenzweig A. Cardiac cell therapy-mixed results from mixed cells. N Engl J Med. 2006;355;12:1274-7.

3. Vulliet PR, Greeley M, Halloran SM, MacDonald KA, Kittleson MD. Intra-coronary arterial injection of mesenchymal stromal cells and microinfarction in dogs. Lancet. 2004;363:783-4.

4. Hou M, Yang KM, Zhang H, Zhu WQ, Duan FJ, Wang H, et al. Transplantation of mesenchymal stem cells from human bone marrow improves damaged heart function in rats. Int $J$ Cardiol. 2007;115: 220-8.

5. He G, Zhang H, Wei H, Wang Y, Zhang X, Tang Y, et al. In vivo imaging of bone marrow mesenchymal stem cells transplanted into myocardium using magnetic resonance imaging: a novel method to trace the transplanted cells. Int J Cardiol. 2007;114:4-10.

6. Amado L, Schuleri KH, Saliaris AP, Boyle AJ, Helm R, Oskouei B, et al. Multimodality noninvasive imaging demonstrates in vivo cardiac regeneration after mesenchymal stem cell therapy. J Am Coll Cardiol. 2006;48:2116-24.

7. Dick AJ, Guttman MA, Raman VK, Peters DC, Pessanha BS, Hill JM, et al. Magnetic resonance fluoroscopy allows targeted delivery of mesenchymal stem cells to infarct borders in swine. Circulation. 2003; 108:2899-904.

8. Bos C, Delmas Y, Desmouliere A, Solanilla A, Hauger O, Grosset C, et al. In vivo MR imaging of intravascularly injected magnetically labeled mesenchymal stem cells in rat kidney and liver. Radiology. 2004;233:781-89.

9. Yasuda T, Weisel RD, Kiani C, Mickle DA, Maganti M, Li RK. Quantitative analysis of survival of transplanted smooth muscle cells with real-time polymerase chain reaction. $J$ Thorac Cardiovasc Surg. 2005;129:904-11.

10. Pittenger MF, Martin BJ. Mesenchymal stem cells and their potential as cardiac therapeutics. Circ Res. 2004;95:9-20.

11. Chen SL, Fang WW, Ye F, Liu YH, Qian J, Shan SJ, et al. Effect on left ventricular function of intracoronary transplantation of autologous bone marrow mesenchymal stem cell in patients with acute myocardial infarction. Am J Cardiol. 2004;94:92-5.

12. Kraitchman DL, Tatsumi M, Gilson WD, Ishimori T, Kedziorek D, Walczak P, et al. Dynamic imaging of allogeneic mesenchymal stem cells trafficking to myocardial infarction. Circulation. 2005;112: 1451-61.

13. Zhou R, Acton PD, Ferrari V. Imaging stem cells implanted in infarcted myocardium. J Am Coll Cardiol. 2006;48:2094-106.

14. ven den Bos EJ, Barks T, Moelker AD, Kerver W, van Geuns RJ, van der Giessen WJ, et al. Magnetic resonance imaging of haemorrhage within reperfused myocardial infarcts: possible interference with iron oxide-labelled cell tracking? Eur Heart J. 2006;27:1620-6.

15. Lee TH, Reed W, Mangawang-Montalvo L, Watson J, Busch MP. Donor WBCs can persist and transiently mediate immunologic function in a murine transfusion model: effects of irradiation, storage, and histocompatibility. Transfusion. 2001;41:637-42.

16. Freyman T, Polin G, Osman H, Crary J, Lu M, Cheng L, et al. A quantitative, randomized study evaluating three methods of mesenchymal stem cell delivery following myocardial infarction. Eur Heart $J$. 2006;27:1114-22.

17. Hou D, Youssef EA, Brinton TJ, Zhang P, Rogers P, Price ET, et al Radiolabeled cell distribution after intramyocardial, intracoronary, and interstitial retrograde coronary venous delivery: implications for current clinical trials. Circulation. 2005;112(9 Suppl):I150-6.

18. Barbash IM, Chouraqui P, Baron J, Feinberg MS, Etzion S, Tessone A, et al. Systemic delivery of bone marrow-derived mesenchymal stem cells to the infarcted myocardium: feasibility, cell migration, and body distribution. Circulation. 2003;108:863-8.

19. Stamm C, Kleine H, Choi YH, Dunkelmann S, Lauffs JA, Lorenzen B, et al. Intramyocardial delivery of $\mathrm{CD}_{133^{+}}$bone marrow cells and coronary artery bypass grafting for chronic ischemic heart disease: safety and efficacy studies. J Thorac Cardiovasc Surg. 2007;133: 717-25.

20. Menasché P, Hagège AA, Vilquin JT, Desnos M, Abergel E, Pouzet B, et al. Autologous skeletal myoblast transplantation for severe postinfarction left ventricular dysfunction. J Am Coll Cardiol. 2003;41: 078-83.

21. Teng CJ, Luo J, Chiu RC, Shum-Tim D. Massive mechanical loss of microspheres with direct intramyocardial injection in the beating heart: implications for cellular cardiomyoplasty. J Thorac Cardiovasc Surg. 2006;132:628-32.

22. Dai W, Hale SL, Martin BJ, Kuang JQ, Dow JS, Wold LE, et al. Allogeneic mesenchymal stem cell transplantation in postinfarcted rat myocardium: short- and long-term effects. Circulation. 2005;112 214-23. 

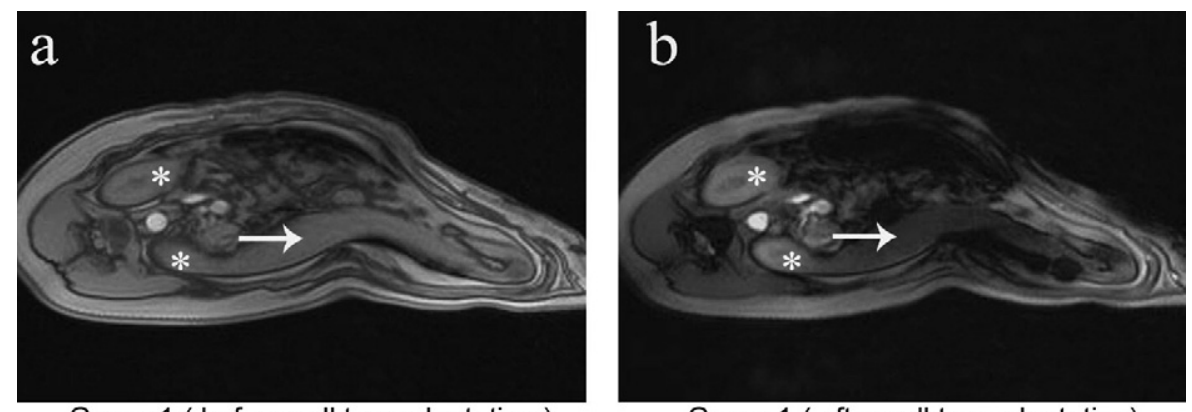

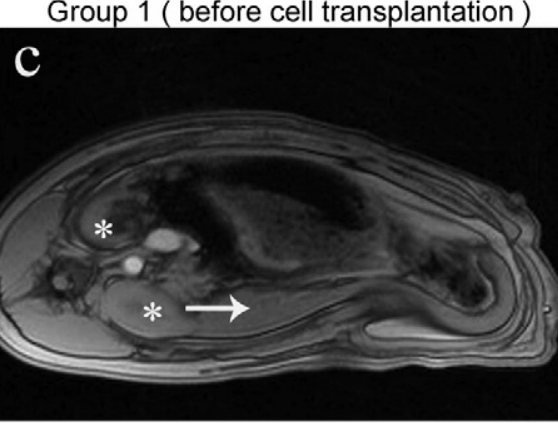

Group 2 ( before cell transplantation)

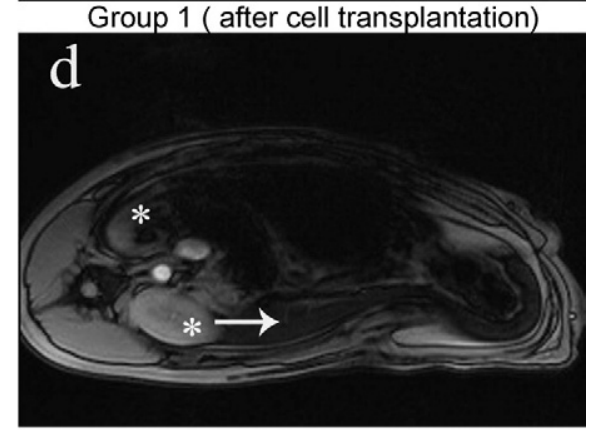

Group 2 ( after cell transplantation)

Figure E1. MRIs of spleen and kidney. The spleen had stronger signal void after cell injection. There was no significant difference in T2* change of the kidney in both groups. Compared with group 1, T2* change of spleen in group 2 was higher. (Arrows represent spleen and stars represent kidney.)

TABLE E1. Comparison of myocardial infarction area and heart function before (Pre) and after (Post) cell or medium injection

\begin{tabular}{|c|c|c|c|c|c|c|c|c|}
\hline & \multicolumn{2}{|c|}{ Group 1} & \multicolumn{2}{|c|}{ Group 2} & \multicolumn{2}{|c|}{ Group 3} & \multicolumn{2}{|c|}{ Group 4} \\
\hline & Pre & Post & Pre & Post & Pre & Post & Pre & Post \\
\hline $\mathrm{Ml}$ area $\left(\mathrm{cm}^{2}\right)$ & $6.5 \pm 2.1$ & $6.4 \pm 2.3$ & $6.4 \pm 1.9$ & $6.2 \pm 2.6$ & $6.5 \pm 2.5$ & $6.3 \pm 2.5$ & $6.4 \pm 2.6$ & $6.4 \pm 2.4$ \\
\hline LVEDV (mL) & $56.8 \pm 5.3$ & $65.2 \pm 5.2$ & $54.8 \pm 6.8$ & $63.2 \pm 3.7$ & $57.4 \pm 4.3$ & $60.2 \pm 4.7$ & $56.8 \pm 2.8$ & $62.2 \pm 4.4$ \\
\hline LVESV (mL) & $33.5 \pm 7.6$ & $37.3 \pm 5.6$ & $32.3 \pm 5.3$ & $36.3 \pm 6.9$ & $33.5 \pm 3.6$ & $34.3 \pm 5.4$ & $32.7 \pm 4.6$ & $36.3 \pm 8.1$ \\
\hline LVEF (\%) & $42.3 \pm 7.2$ & $44.5 \pm 8.7$ & $41.7 \pm 6.8$ & $43.1 \pm 7.4$ & $41.8 \pm 8.6$ & $42.8 \pm 5.6$ & $42.7 \pm 7.7$ & $43.3 \pm 8.4$ \\
\hline
\end{tabular}

$M I$, Myocardial infarction; LVEDV, left ventricular end-diastolic volume; LVESV, left ventricular end-systolic volume; $L V E F$, left ventricular ejection fraction. 